\title{
Entrevista: Peter Kevin Spink
}

Nessa entrevista, concedida a Leny Sato, o Prof. Peter Spink, psicólogo inglês radicado no Brasil, relata-nos sua trajetória, apresenta sua concepção sobre psicologia dos processos organizativos, sobre a função social da psicologia e da universidade e o trabalho que vem desenvolvendo atualmente. Foi professor do Instituto de Psicologia da USP durante 19821985, é professor do programa de pós-graduação em psicologia social da PUC-SP e coordena o Centro de Administração Pública e Governo na Escola de Administração de Empresas de São Paulo da Fundação Getúlio Vargas. Concedida em dois encontros, a entrevista foi realizada na FGV.

Leny Sato - Bom Peter, a primeira coisa que eu queria que você falasse é sobre a sua formação, sua experiência de trabalho antes de vir ao Brasil.

Peter K. Spink - Me formei em psicologia, na University College, Universidade de Londres. Naquela época, o curso de psicologia era de 3 anos, bastante puxado, cognitivo e experimental, mas não profissionalizante. Toda a formação profissional na psicologia inglesa se fazia e continua se fazendo na pós-graduação.

Leny - Então, para exercer a profissão de psicólogo, necessariamente, você teria que fazer uma pós-graduação, é nesse sentido?

Peter - A nossa noção de exercício profissional é diferente à do Brasil. $\mathrm{O}$ curso de graduação é uma formação acadêmica. No Reino Unido, são as sociedades profissionais que regulamentam a formação profissional e dizem quais dos seus membros podem ser considerados psicólogos e em quais áreas podem praticar, entendendo prática aqui no sentido de responsabilização profissional. As áreas se referem - basicamente - às grandes divisões profissionais: aconselhamento, clínica, educacional e trabalho. Para coordenar serviços públicos nestas áreas mais específicas, prestar assessoria ou trabalhar na supervisão de outros, você tem que fazer a pós-graduação e também ter um período de prática profissional supervisionada. A distinção mais importante com o modelo brasileiro é que a profissionalização se vincula a uma área e não a todas, e dentro da área temos que declarar as sub-áreas de competência. Portanto eu sou psicólogo, mas não tenho nenhuma competência nas áreas educacional ou clínica; profissional e eticamente não posso dar nenhum parecer ou orientação para ação nestes campos. A formação básica, portanto, seria equivalente ao bacharelado.

Bem, eu fiz pós-graduação em "psicologia do trabalho", que era chamada "occupational" naquela época (hoje "organização e trabalho") e passei direto para o doutorado, já com intenção de trabalhar com pesquisa aplicada. O uso do termo "occupational psychology" foi uma escolha consciente do grupo de Birkbeck College na Universidade de Londres; naquela época, o único grupo de pós-graduação no país na área de psicologia do trabalho. Alec Rodger quis chamar a atenção à contribuição da psicologia para a pessoa no que tange à sua relação com o mundo de ocupações. Então, aí, foi agregada ao mundo de trabalho e organizações, seleção etc., a área de preparação para o trabalho e a orientação vocacional nas escolas e a vida pós-ocupacional, aposentadoria. Também discutimos muito a relação entre o mundo do trabalho e o mundo fora do trabalho.

Leny - Não é apenas a escolha de uma atividade profissional, mas é a vida de trabalho e a relação da pessoa com essa vida de trabalho. Então, aí, Peter, quando você veio ao Brasil e foi nosso professor na graduação, em 1982, na USP, de fato, na disciplina que você ministrou para nós - orientação profissional -, eu me lembro que a abordagem era bastante ampla: dentro da empresa, fora... 
Peter - Sim, isso era uma conseqüência disso. O motivo pelo qual eu dei Orientação Profissional na USP foi simplesmente porque alguém olhou o meu curriculum - e eu tenho doutorado em "psicologia ocupacional" - e presumiu que isso queria dizer "vocação". Para nós, o trabalho em "psicologia vocacional" seria só uma parte de uma olhada mais ampla, que inclui a ergonomia, desenho de organizações, desenho de postos de trabalho, treinamento, seleção, dinâmica de pequenos grupos, mudança organizacional, tudo, tudo, tudo o que tem a ver com o mundo do trabalho. Porque, essencialmente, se você usa a noção de "ocupação" como a de alguma coisa que você faz e é remunerado para fazer, então você abre um espaço bem grande.

Leny - Ou seja, essa fragmentação que a gente observou e ainda observa no Brasil nos cursos de graduação em psicologia e em muitas práticas profissionais (que você discute no texto da revista da $\mathrm{ABRAPSO}^{29}$ ) -, essa fragmentação em áreas de atividade (e que se presume que o curriculum deva ser assim...), não era o entendimento deste curso que você fez, ou seja, o olhar que você tinha era distinto deste...

Peter - Sim... bastante distinto. Eu era aluno de doutorado. Você podia fazer doutorado direto se você tivesse bons resultados nos exames, mas todos os alunos, de mestrado e doutorado, trabalhavam juntos. Não éramos muitos e a gente fazia tudo junto. As aulas do curso eram à noite, sempre à noite. Por quê? Em parte por uma tradição de Birkbeck College, que foi criado como colégio dentro da Universidade de Londres com o espírito de facilitar o acesso do trabalhador à universidade e teve muita interação com os movimentos de educação popular da esquerda, mas também para que durante o dia nos envolvêssemos em atividades, estágios, projetos aplicados em organizações, em coisas as mais variadas e mais diferentes. Isso foi muito especial. Como o grupo era o único no país, as organizações procuravam o departamento para certos problemas, consultorias ou simplesmente trabalhos de aplicação; ou para oferecer espaço de estágio. Então, de dia, mergulhávamos no campo e, à noite, a gente tinha aula.

Isso fez com que eu aprendesse a olhar as organizações e o trabalho a partir de uma intensa vida de campo. Eu gostava muito. Como bolsista eu era também o assistente de pesquisa do catedrático, eu fazia muita coisa diretamente com ele. E passava horas, e horas, e horas em organizações dos mais variados tipos. Acho que isso me marcou muito. Me deu muito respeito para a competência cotidiana das pessoas, me deu um respeito para a capacidade de as pessoas articularem suas visões sobre o que está acontecendo. Eu trabalhei muito com questões de mudança tecnológica, onde você tem, teoricamente, a situação em que técnicos estão dizendo: "os trabalhadores não sabem", ou "não vão conseguir se adaptar a isso". E você percebe que as pessoas não só sabiam e não tinham problema nenhum de adaptação, mas, ao contrário, que elas estavam muito mais preocupadas com as implicações e conseqüências disso. No Reino Unido, há uma forte tradição trabalhista-sindical local na fábrica, que trata de muitas outras questões além de salariais, e discutir o que está acontecendo com o trabalho é parte disso.

Leny - E o incentivo era para que o aluno ficasse ali, olhando o que acontecia, ficando...

Peter - Ficando... ficando. Às vezes saíamos das aulas direto para algum trabalho de acompanhamento nos turnos noturnos. Todos nós, naquela época, não éramos muitos - um ou dois alunos de doutorado por ano, no máximo; provavelmente dez ou doze alunos de mestrado -, mas todo mundo envolvido nesse tipo de atividade junto com os professores. Você acaba desenvolvendo um espírito profissional crítico, um senso dos problemas e das possibilidades.

${ }^{29}$ Spink, Peter Kevin (1996). A organização como fenômeno psicossocial: notas para uma redefinição da psicologia do trabalho. Psicologia E Sociedade - Revista da Associação Brasileira de Psicologia Social (ABRAPSO), 8 (1), $174-192$. 
Bom, quando eu terminei o doutorado, a última coisa que queria fazer era seguir o caminho natural e entrar na carreira de professor. Eu estava muito voltado a essa noção de um engajamento, enquanto pesquisador, com a prática e a possibilidade de mudança, chegando quase que intuitivamente à noção de pesquisa-ação. Ao conversar com Alec Rodger - que foi o primeiro catedrático no campo na Universidade de Londres - ele respondeu que, basicamente, o único lugar onde eu acharia esta justaposição de pesquisa e ação, naquela época, era o Tavistock Institute of Human Relations, agora o Tavistock Institute. Felizmente, eu procurei o Tavistock no momento em que o Tavistock estava procurando pesquisadores. Isso foi em 1970. Terminei o doutorado durante o período no Tavistock, em parte porque repensei muito as abordagens que estava usando e também acabei incluindo muitos trabalhos aplicados. Foi uma análise da problemática de mudança organizacional e tinha casos, testes, experiências de intervenção e uma variedade de métodos ${ }^{30}$. O Tavistock Institute (naqueles tempos estávamos no mesmo prédio da Tavistock Clinic) era pequeno, nunca foi muito grande. Quando eu cheguei lá, tinha umas 40 pessoas ao todo, nos diversos centros. Seus trabalhos eram mais conhecidos academicamente fora do país do que dentro, em parte por causa do pioneirismo dos temas sendo trabalhados e também da ortodoxia de boa parte da vida acadêmica. Além disso, o trabalho na Tavistock era essencialmente de pesquisa aplicada, feita numa ótica de pesquisa-ação; e sabemos como o trabalho aplicado é normalmente visto! O Instituto se sustentou coletivamente a partir dos trabalhos feitos e os contratos de pesquisa.

Leny - Eu queria que você falasse um pouco mais sobre "pesquisa aplicada", porque a idéia de "psicologia aplicada" aqui no Brasil acabou sendo cunhada de modo bastante distinto do que você chama de "psicologia aplicada" e "pesquisa aplicada".

Peter - Eu não quero discordar das pessoas que gostam de fazer pesquisa de laboratório, a não ser quando buscam mecanismos para marginalizar outras formas de pesquisa. É um jeito diferente de fazer as coisas e as pessoas fazem se acham útil, o importante é a possibilidade de diálogo. Agora, no espaço de pesquisa aplicada, aí sim, eu argumento a favor de uma determinada abordagem. Depois de formado, eu estava diretamente envolvido em pesquisa aplicada; aliás, este interesse começou já no curso de graduação, quando fiz meu trabalho de conclusão de curso sobre as posturas de motoristas de carro de passeio sobre o consumo de álcool. Mas nos anos de Birkbeck e nos trabalhos de campo, eu, gradativamente, comecei a juntar o que para mim era a base de pesquisa-ação. As relações clássicas de assessoria técnica, de relatórios apresentados e discutidos com os níveis hierárquicos superiores das organizações, mesmo com muito boas intenções, não eram adequados. Eu estava querendo algo diferente, especialmente quando eu vi, estudando mudança tecnológica, o quanto os sindicatos de trabalhadores tinham a contribuir para um debate que nunca aconteceu. Lá estava eu, entrevistando os operários e os representantes sindicais, pegando as informações; mas consciente de que essas informações só seriam recebidas e lidas em relatórios, que não havia lugar para a presença ativa dos informantes nem no debate e muito menos na organização e orientação da pesquisa...

Leny - Não cabiam lá...

Peter - Não cabiam nos espaços de discussão hierárquicos nas organizações onde estávamos trabalhando. Eu me olhei um dia no espelho e disse: "a partir desta data eu não faço mais pesquisa a não ser aonde possa ajudar o diálogo entre os diferentes atores presentes!”

${ }_{30}$ Spink, Peter Kevin (1976). Capacity and Inclination for Change: problems of measurement, prediction and facilitation. $\mathrm{PhD}$ Occupational Psychology, University of London. 
Leny - As diversas visões sobre os problemas...

Peter - As diversas partes do quebra-cabeça e as diversas partes hierarquicamente também. Aí eu disse: "bom, eu não sei como isso se chama, mas eu vou chamar de pesquisaação". Aí, conversando com outras pessoas, elas disseram: "mas é isso mesmo!". Não se discutia pesquisa-ação nas universidades; conhecíamos os estudos de Kurt Lewin na área de liderança e pequenos grupos, mas nos cursos de metodologia e no trabalho experimental semanal fomos levados a imaginar pesquisa como no modelo das ciências exatas. Fazer pesquisa aplicada já era mal visto e, dentro da pesquisa aplicada, a idéia de que você pode desmontar as relações de poder, de que você pode incluir o outro no processo de construção do conhecimento, também era totalmente estranho. Não era uma questão de orientação política, porque, em geral, pesquisa aplicada era feita por pessoas com muito boas intenções e tendências progressistas, mas sempre dentro da ótica de "aplicar psicologia a... algo".

O que eu encontrei no Instituto Tavistock era o contrário, iniciando com uma forte ligação intelectual com a postura de Kurt Lewin e com pessoas ligadas à pesquisa-ação em diversos lugares do mundo. Articulamos a idéia de que o caminho do conhecimento não começa na universidade para, então, ir para a área aplicada e depois para o campo, mas, ao contrário: o trabalho começa no campo... as idéias emergem no campo e só depois são transferidos para a universidade. Em vez de situar o trabalho de campo como sendo inferior, fizemos o inverso. Considerávamos que o trabalho que se fazia em boa parte das universidades era inferior, por ser atrasado. Não por arrogância, mas por um aspecto lógico: se você está trabalhando no campo, você está aberto ao que está acontecendo, você está trabalhando com os atores-chaves que estão presentes, você está lidando com as questões que estão emergindo no momento e onde emergem. É só depois que estas questões chegam às universidades. Só chegam quando as pessoas começam a prestar atenção a elas.

Leny - Escrever, dar nome...

Peter - Dar nome... legitimar em termos de preocupações convencionais. As universidades são espaços protegidos e isso quer dizer "não abertos". Não é a sociedade que determina o que a Universidade vai estudar; são raros os momentos como, por exemplo, na PUC-SP, quando Dom Paulo Arns falou com toda a autoridade da igreja e em nome da sociedade.... "universidade para o quê?" E argumentou em termos da opção para o social e para os excluídos.

Infelizmente, a Universidade continua deixando a desejar e está longe de assumir o debate democrático sobre o que estudar e sobre as questões de importância para a sociedade. No Tavistock encontrei um ambiente onde as pessoas, a grande maioria com doutorado, publicavam regularmente e só foram para a universidade mais tarde nas suas carreiras, normalmente convidadas pelas universidades, já para postos mais altos. No Brasil, se fôssemos buscar o mesmo tipo de instituto, olharíamos talvez para alguns dos institutos da área de saúde aplicada, que foram criados no início do século, tipo o Instituto Butantã. Com todas as diferenças que é necessário traçar, existe na história do Butantã esta visão de sair para o campo, começar a mexer com as coisas e elaborar a partir disso.

Leny - E aqui no Brasil, temos pouquíssimos institutos de pesquisa social. A profissão, digamos, de pesquisador no campo social praticamente não existe. Existem alguns na área da saúde, na área da agricultura, alguns poucos na área urbana, mas muito restrito.

Peter - Penso que isso não é por acaso. Na década de 60-70, na Inglaterra, durante o boom político e cultural, nós tínhamos muitos centros de pesquisa aplicada, de diversas formas. O Tavistock era algo especial, mas tinham outros. No Tavistock tinha mais profissionais vindos da psicologia, da antropologia, da pesquisa operacional, da psiquiatria. Esse era o eixo dele, mas tinham outros excelentes centros com grupos nas áreas, por exemplo, de sociologia urbana, de habitação, de assistência social, em outros lugares. Tanto 
que criamos, neste período, uma associação de pesquisa em ciências sociais; foi basicamente todo mundo envolvido nesses centros de pesquisa - que era, de uma maneira ou outra, aplicada - e muitos foram financiados, em parte por contratos de pesquisa aplicada com os diferentes Ministérios do Governo ou de vários governos locais, além das instituições de fomento a pesquisa e outras associações. Uma das primeiras coisas que a Margareth Thatcher fez foi cortar toda a linha de financiamento dos ministérios e agências públicas para a área de pesquisa aplicada, nos quais boa parte do trabalho que estava sendo feito era para o ministério da saúde, ministério da assistência social, do desenvolvimento urbano.

Leny - Para o Estado...

Peter - Para o Estado, sobre problemas reais. O Estado era muito ativo em chamar os grupos de pesquisa aplicada para investigar e abrir as questões para o debate público. Talvez seja possível sugerir que você tem pesquisa aplicada crítica onde você tem democracia aberta - onde você tem um Estado que entende que você tem que discutir os problemas, debater as visões diferentes. Um processo político que precisa das múltiplas vozes.

As múltiplas vozes não têm muito lugar num modelo político fechado, ou de uma democracia de superfície, ou de uma democracia dominada por tecnocratas que já sabem. Acho que isto é algo para pensarmos mais... Por que os poucos grupos verdadeiramente independentes só conseguem sobreviver com o apoio, basicamente, das Fundações e ONGs externos? Por que temos dificuldade em enfrentar e assumir as críticas e o debate como forma de melhorar o conhecimento?... É algo para maior reflexão.

Leny - Por que "psicologia social das organizações"?

Peter - Você me perguntou sobre isso na preparação da entrevista e acabamos chegando lá. Nesta questão da organização da sociedade, da possibilidade de debate e de ter e assumir posições diferentes, muito daquilo que nós estamos apontando acontece em processos organizativos, na interface entre organizações diferentes. Desde o início dos estudos de pósgraduação, eu estava mais interessado na dinâmica social do processo organizativo. Estava mais interessado em estudar questões de moral, comunicação, ação de pequenos grupos, posturas sobre a mudança, como as pessoas entendiam as organizações e muito menos interessado em seleção, treinamento, orientação vocacional - os tópicos, digamos, clássicos. E eu me enveredei mais para me preocupar com a organização do trabalho e com o trabalho, a visão que as pessoas tinham sobre isso e as possibilidades de mudança.

Leny - Que tem relação com o seu doutorado, que era...

Peter - Era sobre capacidade e inclinação para mudança e me levou também para a discussão de mudança não somente tecnológica, mas de mudança organizacional em geral. Como resultado, também me envolvi com o desenvolvimento organizacional e o uso de dinâmica de grupos e de workshops na discussão de possibilidades de mudança e de lá para os processos sociais. Aí eu comecei a batalhar uma noção de psicologia social das organizações, para chamar a atenção para as organizações como processos sociais. Aí foi um pequeno passo para dizer: "por que a gente está só estudando organizações de trabalho?" Porque, basicamente, é isso o que se estuda na psicologia organizacional. É a mesma coisa na Europa e nos Estados Unidos. No Tavistock, nós fazíamos outros tipos de estudo. Olhávamos questões urbanas, fizemos uma série de estudos sobre re-localização de indústrias, re-localização de serviços públicos, tentando entender o que quer dizer "mudar" geograficamente para as pessoas, o que isso implica. Aí você começa a pensar sobre o que quer dizer isso em relação à família, a filhos na escola; o que significa para as pessoas re-estabelecer vínculos depois de mudar de lugar. 
Leny - Esse tema que você está colocando tem a ver com um artigo que você escreveu em um jornal inglês, Journal of Occupational Psychology - "Some comments on the quality of working life" ${ }^{\text {"31 }}$, no qual você discute essas questões de mudar ou não mudar.

Peter - A qualidade da vida dentro do trabalho versus fora do trabalho. Sim. Isso chamou a atenção sobre a visão extremamente restrita que se têm sobre a pessoa no trabalho. Parece que a psicologia é incapaz de pensar sobre uma pessoa 24 horas por dia; inserida numa malha de relações sociais e familiares e com múltiplas inserções organizacionais e institucionais que, freqüentemente, são muito mais importantes para ela. Aí vem a psicologia com toda a parafernália de "motivação" e "comprometimento no trabalho" - parece até totalitária. Por que você tem que exigir que a pessoa ame o seu trabalho, queira se identificar com ele para o restante da vida, queira subir na vida etc...? Como se esse fosse o meio através do qual você sobe na vida. Até a expressão "subir na vida": vida é uma coisa que você sobe? Você poderia simplesmente estar bem de vida: tem peixe no rio, o milho está crescendo bem, o papo no bar é gostoso, você tem tempo para se dedicar a uma associação comunitária e o seu trabalho é uma coisa razoável que você gosta ou não gosta, no qual tem gente com quem você se dá bem, você pega o seu dinheiro no final do mês e vai embora. Quando você coloca desta maneira, fica meio óbvio que estamos olhando processos sociais mais amplos, com milhões de organizações diferentes, e que só uma ínfima parcela tem a ver com trabalho propriamente dito e, dentro da área de trabalho, só uma pequena parte tem a ver com organizações industriais de grande porte, bancos etc.

Leny - Mas isso não pode levar as pessoas a pensar que a qualidade de vida no trabalho é problema secundário?

Peter - Ao contrário, porque chama atenção às interconexões, aos contrastes entre as maneiras em que a cidadania é construída na vida diária e às múltiplas restrições presentes em muitas relações de trabalho. Podemos usar um exemplo que me marcou muito na época do artigo: se você anda na rua e quer telefonar, você pára num orelhão; até pode parar num bar e pedir para usar o telefone. É uma marca da cidadania e solidariedade coletiva do cotidiano pedir para usar o telefone e ter seu pedido aceito com bom grado. Agora imagine isso numa fábrica... quem tem acesso ao telefone e em quais condições? Penso que ampliar o nosso ângulo de visão ajude chamar atenção a estes contrastes e contradições que, de outra maneira, temos a tendência de não enxergar, por considerarmos parte dada do cenário. Há "n" formas através das quais as pessoas ganham a vida - e não são estudadas, mas poderiam trazer uma melhor compreensão sobre a problemática do trabalho dentro dos espaços de vida local, o que inclui aspectos de solidariedade, cooperativismo e ajuda mútua, como também problemas de trabalho escravo e trabalho infantil.

Bem no meio destas reflexões, que não eram em nada lógicas, mas muito mais um processo confuso de pedaços de idéias garimpadas nos múltiplos trabalhos de campo, eu comecei a tecer uma perspectiva possível, um jeito de compreender a questão. Há uma briga falsa na "psicologia organizacional do trabalho" entre os psicólogos ortodoxos - uma parte dos quais ligados às áreas de recursos humanos - e os psicólogos críticos. Mas a briga é sobre quem é o dono teórico e conceitual de um espaço de atuação - trabalho e empresas - que é, para usar uma imagem de um círculo de 360 graus, somente 5 graus do fenômeno. Quem é o dono dos 5 graus? Não estão olhando para o restante nem para as contribuições que isso pode trazer à compreensão de questões bastante complexas. Por exemplo, quando alguém olha uma situação extremamente restrita de trabalho, a clássica descrição do trabalhador oprimido que não tem liberdade de expressão no posto, é exigido nada dele a não ser sua força (literalmente); tem hierarquia pesada em cima, que responde monossilabicamente às suas

${ }^{31}$ Spink, P. K. (1975). Some comments on the quality of working life. Journal of Occupational Psychology, 48, 179-184. 
perguntas. Esta é uma leitura; agora se você fosse olhar os outros 355 graus, você diria: "nossa, a questão é diferente". Trata-se de entender tanto os mecanismos de dominação quanto os mecanismos de resistência, de refletir sobre a loucura da fábrica que faz com que as pessoas sejam forçadas a aceitar situações como essas, sabendo que no restante de suas vidas a lógica é outra. E o mesmo se aplica aos recém graduados nos seus ternos e gravatas, levados também a imaginar que a vida de trabalho consiste em mercado e "manda": "manda" fazer, "manda" não fazer, "manda" contratar, "manda" embora - mas eles também sabem que no restante da suas vidas a lógica é outra.

Leny - É o que você apresenta como argumento inicial no artigo da Psicologia Atual. ${ }^{32}$

Peter - Não são as pessoas que são loucas, são as empresas. Insanos são os modelos de produção.

Leny - E você coloca no artigo que cria-se um desenho, um projeto de organização de trabalho prevendo uma pessoa que não sabe, que precisa ser controlada, sendo que, ao contrário, ela sabe muito e resolve muitos problemas fora do trabalho.

Peter - E resolve muitos problemas dentro do trabalho também. Essa foi a vantagem daquela parte da minha vida em que a gente passava horas e horas, meses e meses nas fábricas. Um dos estudos que fizemos foi para a companhia de automóveis Ford, sobre o futuro do supervisor de produção. O que aconteceria com o papel do supervisor de produção com as novas tecnologias? Durante 3 meses, quase 24 horas por dia, eu vivi em fábricas Ford, não de fazer visitinha, mas de viver nas fábricas, conversando com pessoas na linha, fora da linha, nas áreas de almoxarifado, fundição, funilaria e nos escritórios. Assim, você começa a compreender como se dá a vida diária, os momentos de isolamento, de alienação, os momentos de resistência, de contra-cultura, de ocupação dos espaços. O resultado é uma compreensão muito mais ampla da processualidade do dia-a-dia, algo que busquei trabalhar no texto sobre cidadania e as organizações, que fez parte de uma preciosa coletânea sobre cidadania em construção, resultado de uma reunião da $\mathrm{ABRAPSO}^{33}$.

Agora, segue também um alerta... estes diferentes elementos de uma postura futura sobre psicologia organizacional, que hoje eu posso reconhecer, foram opções e idéias construídas, às vezes, incrementalmente e, às vezes, muito mais por oportunidade do que desejo ou escolha. Mas tem suas conseqüências... se você quer sentir o que é ser uma minoria marginalizada é só seguir o caminho que eu segui. Você se recusa a trabalhar na universidade porque você valoriza a pesquisa aplicada, aí você briga por um tipo de pesquisa aplicada que é co-determinada, com engajamento dos trabalhadores e, além de fazer isso, você vira pra todo mundo e diz: "por que vocês estão focalizando isso de maneira restrita quando vocês deveriam olhar mais amplamente?" No Tavistock tivemos uma expressão que articulou as nossas idéias sobre o porquê da atividade de pesquisa: "para contribuir para os assuntos práticos da vida diária e para a melhoria do conhecimento nas ciências sociais". Você tem que estar se perguntando: "eu estou trabalhando sobre as questões do dia? Se não estou fazendo isso, então por que estou ocupando o tempo dos outros?" Se você faz esta pergunta para muitos dos projetos de pesquisa sendo financiados na nossa área, você logo estará sendo marginalizado; não é uma pergunta fácil e não pretendo dar a impressão que resolvi para mim - ao contrário, ela se coloca diariamente.

Leny - Uma questão óbvia, que todos devem fazer: com esta inserção lá na

\footnotetext{
32 Spink, P. K. (1982). Quando trabalhar é neurotizante. Revista Psicologia Atual, São Paulo, ano V, n 27, 16-20.

33 Spink, P. K. (1994). Cidadania na organização e cidadania da organização: notas para a desconstrução de "recursos humanos". In M. J. P. Spink (Org.), A Cidadania em Construção: uma reflexão transdisciplinar (pp. 105-121). São Paulo: Cortez Editora.
} 
Inglaterra, por que vir para o Brasil?

Peter - Eu vim para o Brasil em 1980, por uma série de razões: foi um bom momento de mudar em termos familiares, a Mary Jane [Spink] estava terminando o doutorado, as crianças estavam numa idade boa e o cenário político estava começando a se abrir. Então foi um pouco de tudo, misturado com a pergunta: "por que não?" Ajudou também o fato de que nós já tínhamos passado um ano aqui, entre 1976 - 1977, e eu já conhecia um pouco a situação em São Paulo.

Leny - Na USP, nesse período, você deu aula onde? Na psicologia?

Peter - Eu fiquei na GV o ano inteiro e na PUC na pós de psicologia social. Na USP eu fiquei um semestre, dei um curso especial que a Carolina Bori me pediu para organizar: "tópicos em psicologia organizacional".

Leny - Eu não estava lá, eu entrei em 1978.

Peter - O curso foi na pós, por causa da questão da língua. E foi muita coisa de Kurt Lewin, porque o Tavistock tinha uma forte tradição Lewiniana, como a USP também tinha na década de 60, mas já tinha sido enterrada... o que é uma outra história. Mas eu gostei da experiência e muitos vínculos foram criados na USP, na PUC e na FGV, especialmente com a Arakcy.

Leny - Até então, você tinha ficado no Tavistock.

Peter - Sim. Aí, em 1980, venho para a universidade, pela primeira vez na minha vida, não como um visitante, mas para ficar; uma mudança de identidade que demorou muito e que ainda é incompleta. Me vejo muito mais como um pesquisador aplicado do que como um professor; gosto de trazer as questões de campo para dentro da sala de aula, mas ainda muito me preocupa a ausência de uma forte tradição aplicada nas ciências sociais (sempre entendi a psicologia como parte das ciências sociais) e a ausência de espaços institucionais independentes para esta atividades e para formar novas gerações de pesquisadores comprometidos com a qualidade da vida diária. Mas temos que fazer o que é possível, que é valorizar os poucos centros universitários e as ONGs de pesquisa. É o que temos...

Leny - E você era muito provocador, né, com os alunos... - pensando na experiência que eu tive como sua aluna. Primeiro, o fato de você não ser brasileiro, isso já causava uma curiosidade extra, ou seja, uma pessoa que tinha uma experiência diferente. E depois, acho que nós estávamos habituados a ter um tipo de leitura sobre o que é psicologia, o que é o psicológico, o que merece ser focalizado. Você trouxe outras questões e eu acho que muitas delas a gente ficava assim, olhando, talvez não entendendo muito bem, aquilo ali tudo. Você vivia pondo "minhoquinha" na cabeça da gente. E você foi professor homenageado naquela turma, acho que foi sua primeira turma na graduação.

Peter - Sim, mas eu vivo colocando "minhoca" na minha cabeça também (risos). O trabalho é este, de colocar "minhoca", é essa a questão, de transmitir um pouco isso. Não deixar que nada presumido seja passado sem questionamento.

Leny - Outro dia, estava conversando com o Sidnei Cazeto. Falávamos do nosso curso de graduação e também de você. E ele se lembrou que você, um dia, havia nos perguntado: "por que o atendimento tem que durar 50 minutos?" Eram perguntas assim...

Peter - Sim, é isso. Eu gostei do período na USP na década de 80 , os alunos eram muito bons na graduação. Naquela época, sem nenhum demérito a nenhum deles, acho que a graduação, especialmente o quinto ano, era bem mais instigante do que o pós.

Leny - E a questão sociotécnica?

Peter - Quando eu cheguei aqui, eu comecei a me engajar com muitas questões de trabalho e empresas, porque foi um período de abertura, havia discussões sindicais, tinha 
possibilidades de mudança no ar, tinha um grau mínimo, muito pequeno, mas suficiente, de abertura para discutir questões empresariais. A saúde do trabalho foi um caminho possível e eu me engajei nesta briga porque pareceu que fazia sentido o fazer. A visão sociotécnica desenvolvida a partir dos estudos do Tavistock nas minas de carvão é o desmonte da idéia de que há uma maneira melhor de organizar o trabalho e que a organização do trabalho é determinada tecnologicamente; ou, simplificando mais ainda, é a negação da idéia de que a parte técnica do trabalho é neutra, independente e separada do social. Não, os dois andam juntos e se produzem conjuntamente. Claro que tem máquinas etc... mas essas máquinas são produzidas por pessoas e são "juntadas" por pessoas. E produtos são montados de acordo com certas lógicas que são feitas por pessoas - e isso é cheio de pressupostos sobre que tipo de posto de trabalho deve existir, sobre as competências das pessoas, sobre como elas devem ser supervisionadas ou como a autoridade deve ser exercida. Essa é um pouco a noção que está por trás do processo sociotécnico: não há uma melhor maneira para nada, simplesmente há opções e essas opções têm conseqüências; você tem que discutir e debater, pesar as opções e dar valor - quer dizer, avaliar - as conseqüências.

É importante dizer que essa visão mais crítica sobre a organização do trabalho sempre foi marginal em todo e qualquer lugar. Ela foi um pouco mais aceita em sua versão mais simplificada - em termos de grupos de trabalho, células, núcleos etc. - do que foi em sua versão mais ampla - que é muito mais a preocupação com a democracia no local de trabalho. Bem, neste período de abertura inicial, tinha pessoas como vocês na área de saúde no trabalho, tinha uma nova geração de engenheiros se formando na Poli, em torno de Afonso Fleury, também preocupada com estas questões. Mas eu sempre estava consciente de que esse tipo de convívio democrático sobre a forma através da qual se organiza o trabalho seria extremamente difícil de se construir numa situação em que nem os sindicatos foram reconhecidos como representantes legítimos dos trabalhadores e onde os trabalhadores foram marginalizados em relação à discussão sobre organização e trabalho. $O$ trabalho sociotécnico mexe significativamente com estas questões, porque é um trabalho de análise e discussão entre todas as partes implicadas e não um exercício gerencial de construir melhores caminhos.

Leny - Essa noção de escolha organizacional...

Peter - Também mexe. Porque ela não permite que se trate o mundo como um problema técnico ou abstrato, mas que se reconheça os valores, as opções culturais, as competências e saberes. Estas idéias, hoje, são bastante esquecidas, mas não penso que isso é simplesmente um problema para a teoria sociotécnica. Tenho a impressão que muitas das teorias que estavam sendo trabalhadas na década de 50 e 60 ficaram meio jogadas para o lado por serem consideradas velhas. É interessante refletir que para a história das idéias, 40 anos é absolutamente nada. Sem dúvida, as idéias foram formuladas na linguagem de suas épocas senão elas não seriam formuladas -, mas podem ser reformuladas na linguagem de nossa época. Há muito a ser retrabalhado...

Leny - A Arakcy [Martins Rodrigues] falou, na entrevista que ela deu para os Cadernos de Psicologia Social do Trabalho ${ }^{34}$, da experiência dela, entrando na área de trabalho e organizações: quando tentava estudar algumas abordagens teóricas, ela não conseguia, porque não considerava tais abordagens satisfatórias. Ela considerava a sociotécnica como a que conseguia explicar os fenômenos e, apenas depois de estudá-la, aí sim, ela conseguiu ler os outros autores, localizando, a partir daí, essas outras abordagens.

Peter - A Arakcy foi tremendamente importante para mim. Porque, mesmo inserido no espaço da psicologia, havia muito pouco interesse numa psicologia organizacional mais

${ }^{34}$ Cadernos de Psicologia Social do Trabalho, 1999, 2 (1), 73-84. 
crítica. Eu acabei me voltando mais para discussões no campo de teoria organizacional, onde temos, na GV, um grupo sólido e com expressão significativa. Só não desisti da psicologia por causa da Arakcy e penso que era o mesmo com ela. Arakcy e eu formamos uma dupla que achava que era possível criar uma outra psicologia dos fenômenos organizativos, cada um a seu modo; mas pelo fato de termos mantido sempre contato, continuamos achando possível. Nós nunca trabalhamos juntos, provavelmente porque nossos estilos de pesquisa são diferentes. A Arakcy sempre foi muito mais meticulosa e cuidadosa nas suas pesquisas, produto talvez da sua formação psicanalítica. Eu tenho um estilo de catar tudo e combinar pedaços de métodos com muita reciclagem de coisas achadas no caminho... Mas a gente sempre manteve muito contato; penso que a presença de um para o outro foi uma maneira de dizer: "é possível"...

\section{Leny - Ela fortalecia...}

Peter - Fortaleceu a noção de que era possível pensar assim, independentemente das posições em contrário. Para muitos, as únicas saídas eram para influenciar as macro questões e nós estávamos demonstrando que era possível alterar o dia-a-dia das pessoas. Eu passei algumas idéias para a Arakcy e ela me lembrava de uma série de coisas do Kurt Lewin; eu discutia uma série de idéias de pesquisa com ela, ela me devolveu uma série de questões e assim foi. A gente ia ficando sempre meio em contato, mesmo depois que ela se aposentou na FGV e foi para a USP. Bancas de mestrado e doutorado eram sempre ótimas desculpas para a gente se encontrar!

Leny - E ela falava assim: "Ah, Leny, eu comecei a ministrar, na minha disciplina, a teoria sociotécnica" (acho que na GV) e ela disse que chegava falando que não estava ali pregando a revolução socialista. Então, o que ela dizia era que, dependendo do espaço onde se discutia a sociotécnica, ou você era visto como quem pregava a revolução socialista ou, num outro espaço, como quem estava sendo reformista.

Peter - Exatamente... talvez isso seja a marca de uma boa teoria, aquela que consegue de fato mexer com as posições assumidas. A Arakcy coordenou a tradução de muitos dos trabalhos clássicos sobre a teoria sociotécnica e tentamos achar um editor, na época, mas como nós éramos nem seis e muito menos meia dúzia, ficamos no caminho. Também a abertura empresarial para o debate começou a se fechar numa onda de pensamento bastante neo-liberal, com modelos e receitas prontas - sem espaço para discutir alternativas.

Aí, gradativamente, fui retomando o meu interesse bem anterior sobre questões urbanas, de políticas públicas, de retomar a questão da área pública e me envolver com mudança organizacional na área pública. Assim, gradativamente, fui chegando a muitos outros tipos de organizações e movimentos sociais presentes no espaço público.

Leny - E aí, deve ter uma série de motivos que levaram você a voltar-se para a área pública e a sociedade civil. Talvez em função mesmo da sua concepção sobre processos organizativos - que não é trabalho apenas - e, depois, em função de uma certa resistência, que você observou em relação a processos nos quais diversas visões fossem contempladas na discussão sobre mudança organizacional em empresa privada. É mais isso que fez com que você resolvesse focalizar mais a sociedade civil, movimentos sociais e área pública?

Peter - Sim. Eu vi que, curiosamente, na medida em que vai crescendo a democracia brasileira - ela é ainda pequenininha, mas ela vai batalhando -, você vai abrindo possibilidades de discussão. Enquanto isso, na área empresarial, basicamente no mundo inteiro, ela guindou para um mono-modelismo, um modelo com uma série de pressupostos que não somente são criticáveis em termos ideológicos, mas podem ser negados, pois são logicamente falsos. Não se sustentam nem nas próprias pesquisas do campo administrativo e organizacional - são versões circulantes sem conexão e diálogo, servem para dar identidade 
ao mundo gerencial e para justificar os horrores que temos testemunhado nas práticas das empresas brasileiras nos últimos 5, 6, 7, 8 anos.

Aí chega um momento em que você vai dizer: "bom, remar contra isso é impossível. Eu não vou participar de algo com o qual eu discordo plenamente!". Hoje tenho dificuldade em entender como alguém pode trabalhar com as grandes empresas que estão aí. As visões de mundo dos seus corpos gerenciais são realmente... para além... não vou dizer retrógrada porque não são nem retrógradas, mas estão indo para um espaço que é extremamente complicado, de desconexão com os processos sociais que estão em volta, de uma reificação empresarial que traz um grave determinismo, que é assustador! O Max Pagès ${ }^{35}$ foi muito correto na discussão das organizações hipermodernas. Quando um campo - o campo empresarial, vamos chamar assim - mantém um grau mínimo de abertura, discussão e diálogo, você pode e deve se engajar nesse diálogo, mas quando ele adquire características de uma seita e volta-se para si mesma, não tem nada que se possa fazer. Se alguém quer crer numa visão restrita do mundo e se recusa a aceitar a possibilidade de diálogo, penso que, eticamente, o que você pode e deve fazer é, simplesmente, virar e ir embora.

Leny - Às vezes dá a impressão de que não tem muito espaço para se ter um argumento contrário, não tem.

Peter - Concordo... então se não tem, não tenta! Por exemplo, eu me recuso a orientar trabalhos na área empresarial. Não é uma questão de briga de poder, é a exigência de um mínimo de respeito para a possibilidade de crítica e contra-crítica. Tem que ter a possibilidade de um agir comunicativo. Se não tem...

Leny - Esse jeito de funcionar está cada vez mais... esse controle simbólico está cada vez mais fortalecido.

Peter - Sim. Eu tenho tido conversas com pessoas em que eu tenho que me segurar para manter o mínimo de respeito, porque é absolutamente impressionante! Parecem seitas totalmente voltadas para si, concebendo o mundo nos seus termos e se recusando a imaginar alternativas. Há diálogo nestas condições? Vamos voltar aos nossos 5 graus versus 355 graus. Pragmaticamente, se não há diálogo com os 5 graus, vamos para os outros 355 graus, onde há diálogo, preocupação em buscar respostas, problemas para serem resolvidos e muita coisa para aprender. É lá que eu estou trabalhando e onde os orientandos também estão trabalhando. E você também está fazendo isso. No momento em que você saiu do consultório, da sala de atendimento e foi sentar no pátio do hospital ${ }^{36}$, você também estava fazendo a mesma mudança para os 355 graus. Então, me parece que as pessoas que estão trabalhando nesses 355 graus estão produzindo coisas muito interessantes, estão dialogando sobre fenômenos sociais.

Precisamos ter a coragem de dizer: "sim, há vida além das grandes empresas" e é uma vida muito mais aberta para discussão e debate. Precisamos assumir os 355 graus como o ponto de partida para uma psicologia dos processos organizativos e não os 5 graus das empresas. Mas como fazer isso? Então eu comecei a pensar: "o que eu faço?" Continuo escrevendo artigos críticos sobre esta visão restrita da psicologia organizacional e do trabalho ou começo a montar a alternativa a partir dos 355 graus? Neste momento, fui convidado a passar uma semana na Universidad Central de Venezuela, em Caracas, com o grupo de psicologia social crítica e decidi assumir a ruptura. Dei o título de "a outra psicologia

\footnotetext{
35 Pagès, Max [et. al.] (1993). O poder das organizações. São Paulo: Atlas.

36 Trata-se do projeto de pesquisa elaborado por Leny Sato sob orientação de Peter Spink, intitulado Ideologia de Trabalho e ocupação e sua função no processo de "de-doencificação" de pacientes psiquiátricos. Hospital Psiquiátrico da Água Funda, 1983.
} 
organizacional: sociedade civil e cidadania" e simplesmente comecei! Aí, na PUC, eu fiz a mesma coisa, tanto no meu seminário, quanto na discussão com os alunos e membros do núcleo de organização e ação social, no qual muitas das idéias estavam sendo formuladas. Passei seis dias em casa, com todo o meu material espalhado no chão. Joguei muita coisa fora, organizei o curso. Consegui dar um curso no qual eu não falei nada daquela primeira psicologia organizacional, simplesmente a ignorei.

Agora descobri que, no final, eu posso voltar à questão empresarial, mas muito mais a partir da construção dos espaços privados, a privatização dos espaços públicos, a restrição do exercício da cidadania a essa tendência seitista. Então é possível problematizar a própria insanidade do modelo empresarial, mas a partir de uma outra base: a psicologia dos processos organizativos do dia-a-dia.

Leny - Isso deve ter sido importante, poder dar ou mudar o nome das coisas. O fato de você falar "processo organizativo", ao invés de "organização", propõe uma outra coisa para ser olhada - a possibilidade de ver aquilo que está em movimento e não o que está preso e congelado. Isso você discutiu naquele artigo "O resgate da parte ${ }^{37 "}$.

Peter - Sim, aquele artigo talvez marque o início deste outro jeito de pensar. Eu gosto do termo "processo" ou "processos organizativos", porque chama atenção ao movimento, à ação e à interação de pessoas. Não é um "ente", a organização, dentro da qual o comportamento acontece - são ações e atividades em si. Isto foi algo que eu aprendi muito no Tavistock: prestar muita atenção na busca das palavras mais úteis para tentar transmitir aquilo que você quer falar, que você acha que está presente.

Leny - Você vem de um país onde tem muitos escritores universalmente famosos (risos)...

Peter - E tem muitos dicionários, palavras de origens diferentes - e talvez por isso somos construcionistas natos... Por exemplo, usamos em inglês duas palavras: "liberty" e "freedom" para, juntas, comporem uma noção básica de identidade cívica, enquanto em português usamos somente "liberdade". Mas "liberty" e "freedom" não são intercambiáveis, não são sinônimos, usamos as duas juntas: "liberty and freedom" ...por quê? Isso também faz parte da outra psicologia organizacional!

Leny - Nessa segunda parte da entrevista, Peter, gostaria que você falasse sobre o trabalho que vem desenvolvendo atualmente.

Peter - Eu sempre vi a psicologia do trabalho, a psicologia das organizações, no sentido mais amplo, a partir da psicologia social. Se você me perguntar o quê que eu sou, eu sou mais psicólogo social do que outra coisa. E, com isso, eu consigo olhar o trabalho também de uma forma que não quer dizer "remunerado", "não remunerado" ou da forma mais restrita que as pessoas normalmente vêem. Quando você age junto ao movimento social para fazer alguma coisa, isso é ação, atividade, trabalho. Você está produzindo algo. Então, para mim, era talvez meio natural ampliar o enfoque e pensar não simplesmente a organização empresarial ou a organização pública, mas pensar sobre outras formas de organização, além dos textos sociais mais amplos dentro dos quais estas noções surgem: sociedade civil e tudo mais. Aqui tive a grande vantagem de poder trabalhar em duas frentes: a primeira foram todas as dissertações e teses produzidas por pessoas envolvidas com o Núcleo de Organização e Ação Social que se formou na PUC, entre as quais você foi uma figura importante. O Núcleo é uma fonte constante de novas discussões e novas temáticas. A segunda vem, mais especificamente, a partir da área pública. Eu sempre tive contato com a área pública e uma

${ }^{37}$ Spink, P. K. (1991). O resgate da parte. Revista de Administração, São Paulo, 26 (2), 22-31. 
preocupação com a construção e com a consolidação da democracia. Sempre pensei que temos, como psicólogos, algo a contribuir para isso. Democracia não pertence a ninguém, pertence a todo mundo, então você tem que dar a sua contribuição. E foi isso que me levou a trabalhar na área de reforma administrativa, no Brasil e em outros países, buscando pensar sobre mudança organizacional em termos das conseqüências para a cidadania. O Programa Gestão Pública e Cidadania da Fundação Getúlio Vargas emergiu no meio desse processo.

Foi uma sugestão da Fundação Ford, que basicamente veio para o Centro de Administração Pública e Governo da FGV com uma proposta. A proposta era se nós achávamos relevante criar, no Brasil, um programa para identificar e disseminar práticas inovadoras em governos sub-nacionais brasileiros, estados e municípios, usando como base um prêmio. $\mathrm{O}$ prêmio em si seria somente a metade da história; a outra metade seria a disseminação e produção de conhecimento a partir disso. Nós conversamos muito sobre tudo isso e decidimos que seria interessante, desde que pudéssemos discutir a eficácia e a efetividade da administração pública a partir da ótica da cidadania e reconhecer que nos governos sub-nacionais brasileiros também estão incluídos os governos próprios dos povos originários ou indígenas. Para nós, não é uma questão de simplesmente ser mais eficaz e mais eficiente na área pública, porque os problemas são muito mais substantivos. Trata-se de fazer isso de uma maneira que tenha uma conseqüência positiva para a construção da cidadania. Por isso, o título do projeto: "Gestão Pública e Cidadania". Hoje, estamos no sétimo ano do programa e temos apoio não só da Fundação Ford, mas também do BNDES e já estamos com mais de 5.000 experiências registradas e sendo disseminadas através do banco de dados, vídeos e muitas publicações diferentes - incluindo radionovelas distribuídas para as rádios comunitárias.

Estou muito feliz com os resultados do programa. O programa me permitiu fazer algo que eu sempre quis achar uma maneira de fazer, que é valorizar significativamente, quer dizer, dar prioridade e destaque às inovações naturais, inovações autóctones, aquilo que nasce do chão das pessoas que estão lidando com as questões e, a partir disso, criar um diálogo diferente com a universidade, diálogo no qual as experiências falem. E a gente tem que se perguntar o que isso quer dizer, quais as implicações disso, e não o caminho inverso, onde a gente bola a idéia e tenta achar alguém para aplicá-la. Também a ênfase na disseminação tem sido muito importante para desmontar os nossos próprios vieses acadêmicos. Eu me sinto mais feliz de ver uma radionovela ser tocada em 300 rádios comunitárias contando experiências interessantes ou de ajudar a produzir um vídeo no qual os atores sociais mostram e contam o que fazem diretamente, sem um comentarista ou interlocutor, do que ver o meu artigo publicado em revista científica.

O Programa Gestão Pública e Cidadania tem uma abordagem aberta para todas as áreas possíveis de atuação pública e cada experiência tem muito, mesmo, a contar. Poderia passar o restante do dia lhe relatando. Trabalhamos junto com outras Universidades e ONGs na avaliação dos projetos inscritos e no processo de publicação. Anualmente, fazemos trinta estudos de caso antes de escolher os finalistas do prêmio e todos são feitos por alunos de mestrado e doutorado, que é uma experiência maravilhosa de pesquisa aplicada.

Em 1998, começamos a prestar mais atenção à maneira pela qual as temáticas da pobreza e exclusão social estavam sendo tratadas nos programas e projetos. Naquele momento, a discussão no país era meramente macroeconômica e nos perguntávamos: "será que é só isso? Quais as possibilidades de redução da pobreza no nível local?" Sabíamos que um dos caminhos eram as experiências. Mas também sabíamos que os acadêmicos também eram parte da questão, os técnicos e as ONGs. Bolamos essa série de eventos que foram financiados pela Fundação Ford, os quais Ilka Camarotti, que veio trabalhar com a Marta Farah e eu, chamou de "reunião de confrontação" - usando "confrontação" no sentido francês da palavra: de confrontar idéias e posições. Eram eventos de dois dias, nos quais atores sociais diferentes sentaram em volta da mesa, em grupos de 30 - 40 pessoas, para 
discutirem a temática da pobreza a partir de suas perspectivas, sejam acadêmicas, de ONGs, de movimentos populares e, mais importante, de experiências locais; discutir as experiências, escutar as teorias. Esse processo foi extremamente rico.

Gradativamente, conseguimos achar o caminho da discussão; ao todo foram mais de 160 pessoas envolvidas. E os resultados publicados, com circulação ampla, foram muito importantes. E, desde aquela época, nós continuamos com isso e duas ou três vezes por ano a gente inicia um processo que é tomar um tema que consideramos que deva ser mais trabalhado, buscar casos, experiências que tratem desse tema, pedir para as pessoas estudálas, aí trazer os protagonistas dos casos, os pesquisadores, as autoridades nesta temática, pessoas de organizações internacionais, acadêmicos, "ongueiros", todos juntos, em dois dias de debate. Fizemos sobre a problemática da pequena produção, fizemos três sobre a temática de alianças e parcerias na redução da pobreza, estamos preparando um agora sobre gênero nas políticas públicas e um em outubro, no âmbito da América Latina, sobre as implicações das novas formas de relação entre Estado e sociedade civil, que vai usar casos da Colômbia, do Chile e do Brasil. Brasil?

Leny - Esse programa, Peter, que a Fundação Ford sugeriu para vocês da GV é só no

Peter - Nosso trabalho é somente no âmbito sub-nacional, no Brasil. Mas há programas similares nos EUA, entre as nações indígenas dos EUA, nas Filipinas, África do Sul, Chile, México e China - que está permitindo, mesmo com enfoques diferentes, a elaboração de idéias e a comparação de muitas experiências super interessantes. Agora, vamos experimentar os primeiros passos e ver se é possível juntar diferentes atores sociais de diferentes países em debate, cruzar barreiras culturais e lingüísticas dentro da América Latina.

Agora, eu vou fazer uma pergunta para mim, que é uma pergunta que as pessoas fazem, direta ou indiretamente: "Peter, mas isso é trabalho de psicólogo social?"

Aí eu respondo que sim. Pelo menos não me sinto adotando uma outra linguagem, uma outra disciplina acadêmica. A nossa equipe é interdisciplinar e todos enfatizam aspectos diferentes. Minha parte é menos voltada às políticas públicas; no trabalho sobre pobreza não estamos tentando trabalhar questões macroeconômicas e nem reordenar as instituições políticas, nós estamos tentando trabalhar no micro ou no nível mesmo de ação do cotidiano. A preocupação é pensar sobre o que é possível ser atingido por muitos dos atores locais que estão presentes no cenário. Na medida em que se olha as maneiras pelas quais se constrói a pobreza no dia-a-dia, olha-se os microprocessos organizativos que fazem isso. Nos estudos sobre cadeias de produção, você se defronta com cooperativas de produtores de castanha que, com o apoio do governo (nesse caso, Amapá), agora fabricam biscoitos que são comprados para a merenda escolar e exportam as nozes para a Europa - onde antes trocavam a castanha por leite e não recebiam dinheiro nenhum. As economias de troca são muito presentes nas áreas urbanas e rural, mas tem seu lado, às vezes, bastante negativo, quase de escravidão. Em muitas partes do país, os pequenos produtores são subjugados nesse processo. Então o que é isso, do ponto de vista da psicologia? São pequenas soluções organizativas, são os jeitos através dos quais as pessoas estão conseguindo negociar sentido um com o outro, redefinir relações, alterar lógicas de poder. Está perfeitamente dentro da psicologia. Eles estão mostrando que se pode mexer com o assumido, com o fato dado, que eles não estão taking it for granted. E eu vejo isso como algo muito importante, que tem influenciado tudo o que tenho escrito na psicologia recentemente.

Leny - E essas reuniões confrontativas são um dos exemplos em que esta diversidade de visões que fazem parte dos processos organizativos se apresentam.

Peter - Sim. E demonstram que o cotidiano é um processo de negociação constante de sentidos. Pessoas podem assumir como fato dado aquilo que é assumido como fato dado; 
mas podem não assumir, podem contestar - e contestam muito mais do que percebemos. A psicologia social dos fenômenos organizativos - a "outra" psicologia organizacional - pode ajudar a aprender a desconstruir a lógica destas relações de dominação, estas obviedades que não são óbvias. Mas não se pode somente parar e dizer: "olhe... que horror! Que... situação terrível", escrever dissertações e teses mostrando como as coisas são ruins para as pessoas em situação de pobreza. O Sebastião Salgado faz isso bem melhor e com muito mais clareza e impacto. Nossa obrigação, enquanto psicólogos, é de colocar algo no lugar, de entrar no campo para ajudar na negociação de sentido, de ajudar o fortalecimento das experiências autóctones, incluindo as situações onde há um conflito total de sentidos, onde é necessário aprender rapidamente as artimanhas do poder.

Leny - Isso acontece também nas reuniões abertas que vocês fazem?

Peter - Sim, mas estamos ainda aprendendo. Na última reunião que nós fizemos, tivemos mais de 120 pessoas juntas. Você vai perguntar: "isso é uma reunião"? Sim, mas tivemos que aprender como organizar estes micro eventos. São estruturados quase como se fossem reuniões de cidade, no sentido muito antigo da palavra. São círculos ou quadrados, concêntricos.

Leny - Um dentro do outro...

Peter - Sim, e as pessoas que estão apresentando o caso tendem a sentar no primeiro quadrado, se quiserem; mas depois sentam onde é mais confortável. E fora duas ou três falas, que são estruturadas - o apresentador do caso, o comentarista do caso -, o resto é "pela mão", onde as pessoas se inscrevem, faz-se uma lista e segue-se a lista. Pegamos algumas idéias de reuniões de pequenas cidades de democracia direta, de democracia coletiva...

Leny - Uma arena.

Peter - Sim, a dificuldade é segurar todo mundo, mas as pessoas vão aprendendo que se eu falo demais, eu oblitero a possibilidade de o outro falar - e tem que falar o que é importante falar e não "encher lingüiça" -, então tem sido muito, muito rico.

Leny - E aí, Peter, acho que tem duas questões que aparecem. É um programa que está focalizado na atuação do Estado, gestão pública...

Peter - Ele começou com a atuação do Estado, a gestão pública. Agora, aprendendo a partir das experiências, se expandiu para olhar o que talvez possamos chamar de tentativas e lugares de redefinição do público. Então, por exemplo, o que você faz quando você tem uma experiência comunitária de recursos hídricos, de gestão comunitária para a distribuição de água, e as pessoas falam o seguinte: "na comunidade isso é respeitado porque é público. E é público porque a gente garantiu que nenhum prefeito fez seu nome a partir deste trabalho. Se as pessoas soubessem que esse programa é da prefeitura, elas teriam depredado, mas não depredam porque é público". O que está acontecendo aqui: as pessoas estão redefinindo o que é "público". Esse é um caso. Num outro caso, a situação pode ser totalmente ao contrário: a prefeitura pode ser extremamente ativa, e um secretário municipal pode estar dizendo: "eu entendo que essa atividade é pública, porque nós estamos trabalhando diretamente com os catadores de materiais recicláveis, tomando as decisões juntos, as estratégias que nós estamos elaborando são co-determinadas e com envolvimento de outros, e nós sabemos o que é público, uma ação pública". Então, a redefinição do público acontece em formas diferentes.

Leny - E de políticas públicas também, né? Porque a idéia que se tem é de uma política que vem a partir de um órgão do Estado e que vai descendo. E se você discute o que é público, discute o que é política pública.

Peter -É, exato, e aqui entra o psicólogo social. Há uma diferença entre as políticas públicas e as políticas do público, não no sentido institucional ou societal da ciência política 
ou da sociologia, mas no sentido prático do cotidiano. Até que ponto há, na prática diária, políticas públicas? Será que tudo não é melhor explicado em termos de práticas públicas? Uma política de construção de creches é, no cotidiano, uma creche na esquina da rua com uma diretora que pode, se quiser, trabalhar muito perto da comunidade local ou, mudando de circunstâncias, ter que negociar com a comunidade local, porque esta é forte, é bem organizada para exigir atenção. São práticas...

Essa idéia que você mencionou, de uma política formada que vai descendo e sendo implantada por servidores públicos - que é a idéia circulante sobre as políticas públicas -, não é o que você encontra. É igual a discutir estratégia de futebol. No "frigir dos ovos", o negócio é marcar gol e é isso que as pessoas estão tentando fazer - em termos equivalentes - em termos das questões extremamente sérias da vida diária. As pessoas acabam criando novos espaços, novas possibilidades de relação, às vezes por razões extremamente positivas e às vezes por falta de recursos, mas fazem. Por volta de $80 \%$ das experiências que coletamos demonstram a presença de outras organizações trabalhando junto com a secretaria ou agência em questão, muitas vezes outras organizações públicas e muitas vezes organizações da sociedade civil. Em quase 50\% dos exemplos há a presença dos dois.

Leny - E as empresas, elas também estão presentes?

Peter - Sim, mas de maneira local. São as empresas do bairro, do lugar, muito mais do que as empresas do "marketing social". Aliás, a forma como se reificou a linguagem empresarial para que as pessoas imaginem que elas existem num mercado separado à sociedade, que há uma espécie de espaço livre onde podem escolher em qual área social querem atuar, é assustadora! É muito difícil desconstruir o "mercado" para as empresas e dizer: "não, vocês estão em sociedade!...” É muito difícil. É por isso que eu sou contra noções como "terceiro setor", porque essas noções fetichizam. Leva as pessoas a imaginarem que você tem o primeiro, o segundo e o terceiro setor e que eles são diferentes entre si. Então o primeiro setor é o Estado, o segundo setor são as empresas e o terceiro setor é... sei lá o que é, como se fossem mundos à parte com conjuntos de relações distintas, como se fosse possível ter relações puramente terceiro setoriais - é uma separação falsa. A sociedade não é feita de fatias de bolo.

Leny - Assim, como você estava falando, se na lógica empresarial o mundo é o mercado e não a sociedade, essa mesma lógica pode ser transposta para o Estado e para o terceiro setor, com seus pedaços.

Peter - Com seus respectivos pedaços. E no dia-a-dia, relações econômicas, relações políticas e relações de solidariedade, indivíduos em comunidades são co-presentes, o cotidiano é um processo denso. Por isso, tenho argüido que não há nada além do cotidiano, não há nada além da parte. Organizações voluntárias contratam secretárias, preenchem formulários do Estado e se registram! E as empresas? O que dá direito pra elas funcionarem? É o Estado! Aí as empresas vem com esse papo de que estão num lugar chamado mercado, que não tem nada a ver com o Estado. Se elas existem, é porque antigamente os reis, que eram o Estado, assinavam um documento dizendo: "você pode". Então é necessário para a gente, enquanto psicólogos sociais organizacionais, sermos inquietos com qualquer tentativa de arrumar esses espaços em pacotinhos bem arrumadinhos... todos eles, incluindo o Estado. $\mathrm{O}$ Estado é um arranjo de governabilidade construído num determinado momento do tempo para lidar com determinados problemas de poder e conflito, não tem nada intrinsecamente bom em ter um Estado; há sociedades sem Estado e a gente esquece que um dos trabalhos pioneiros sobre a antropologia política, de Pierre Clastres $^{38}$, foi feito aqui no Brasil.

38 Por exemplo, no livro: Clastres, Pierre (1982). Sociedade contra o Estado: pesquisas de antropologia política (2ª ed.). Rio de Janeiro: Francisco Alves. 
Igualmente, não se pode fazer uma separação simples entre as instituições e as organizações como se fez na psicologia para tentar criar uma área de atuação menos infiltrada pelo capitalismo, há tanto capitalismo na escola pública do bairro ou no posto municipal de saúde quanto num centro empresarial. Fatiar o mundo social é um perigo...

Leny - Não "taking it for granted".

Peter - O fato de que nós estamos sentados numa sala que é chamada "sala de reunião", te demonstra como reunir não é considerado algo corriqueiro. Você tem que ter uma sala para reuniões, quer dizer, o jeito que você trabalha normalmente não é reunido! Ela é um produto... é sociotécnico, mas o técnico é social. Talvez uma conclusão para pessoas como você e eu seria: "don't take it for granted!"

Leny - Sim, é uma construção.

Peter - É uma conseqüência técnica de uma construção social.

Leny - Você estava falando da experiência das reuniões, a arena pública - e eu acabei cortando; mas eu gostaria que você falasse um pouco mais sobre as leituras negociadas, sobre os temas que são discutidos nessas reuniões.

Peter - A gente está tentando coletivizar o conhecimento. As pessoas às vezes criticam, pois acham que teria que se elaborar uma teoria, mas nós não estamos nesta fase. Temos algumas idéias temporárias, alguns posicionamentos iniciais e, com isso, a gente vai ter que andar, pode ser que seja mais para cá do que para lá. Não estamos - isso é muito importante dizer e frisar - não estamos interessados em melhores práticas. A idéia de estudar casos que estão, de uma maneira ou outra, funcionando é a de aprender, não é a de copiar. É a de se engajar em trabalho comparativo que ajude a pensar o que é importante e o que não é importante. Eu diria que você pode chegar às mesmas conclusões, teoricamente, a partir de fracassos ou desastres. Se há coisas a serem pensadas em termos de práticas, tanto faz... Estudar coisas que parecem que estão indo bem é mais simpático... valoriza os atores também, porque foram essas pessoas que fizeram as coisas. Num país onde há muita coisa complicada, é muito gostoso trabalhar com os atores sociais que estão tentando achar caminhos parciais e acompanhar a troca destas experiências, independentemente de partido político. Penso que, de maneira humilde, estamos iniciando o redesenho da relação da universidade com a sociedade. Temos tido reuniões com 110, 120 pessoas, com pessoas do PSDB, do PFL, do MST, com governadores de estado e com a Pastoral da Criança, ou seja, todas as pessoas envolvidas com determinadas questões, compartilhando os sucessos e fracassos de tentativas de construir práticas públicas úteis... pessoas que, com todas as diferenças, são extremamente respeitosas umas com as outras. Por quê? Porque é o respeito das pessoas que fazem coisas para com as pessoas que fazem coisas. É o respeito das pessoas que tentam buscar soluções para com os seus pares... o respeito está no fato de tentarem agir e buscar saídas.

Leny - Independente da posição política, mesmo se for totalmente oposta...

Peter - Sim... Muito bacana isto.

Leny - Você começou a sua entrevista, na primeira parte, falando da importância que teve na tua formação o fato de você ter tido, na pós-graduação, muito espaço para estar nas empresas, estar com as pessoas, estar com os trabalhadores, e que isso fez com que você aprendesse a ter um respeito muito grande pelo que as pessoas normais e comuns pensam, como elas resolvem suas vidas etc... e parece que isso está presente nesse jeito que vocês têm construído agora, nessa conversa entre as pessoas.

Peter - Tá, tá presente.

Leny - E mesmo quando você me mostra o vídeo que vocês estão produzindo, no qual são as pessoas diretamente envolvidas nessas atividades que falam e não os acadêmicos. 
Peter -É, não tem nenhum narrador, nenhum professor, nada.

Leny - Acho que é o [Harold $]^{39}$ Garfinkel quem fala que não existe diferença entre sociologia profissional e sociologia prática e que quando os sociólogos falam de um acontecimento da vida cotidiana, ordinária, corriqueira, eles falam aquilo que as pessoas mesmas falam, só que com outras palavras.

Peter - Exato, e tratam as pessoas como idiotas, incapazes de falar as coisas a não ser que sejam traduzidas...

Leny - Como idiotas culturais.

Peter - É isso... A desigualdade brasileira não vai embora a não ser que reconheçamos que não há ponto neutro no pedaço. Ou o trabalho da gente está contribuindo para reduzir a desigualdade ou ele faz o contrário. Não tem meio termo: ou as nossas ações estão mantendo e aumentando a desigualdade ou estão reduzindo. E a desigualdade se dá em toda uma série de esferas, de relações diferentes, presentes no dia-a-dia.

Leny - Na academia... Você também falava, na primeira parte, da diferença entre o trabalho do Tavistock e da universidade. Que na universidade as coisas demoram pra chegar e também pelo jeito que a universidade se abre para as coisas: muito mais pra falar pelo outro do que deixar falar e pronto, né?

Peter - Há dois ou três anos atrás, eu participei de um encontro de pessoas da área de estudos organizacionais sobre a universidade no final do milênio. $O$ encontro foi muito interessante, pois foi o tipo de encontro que você não participa a não ser que você escreva um paper, e os papers eram todos avaliados. Cem pessoas foram convidadas a participar. Então todos tinham o paper de todos que estavam lá. E foi muito interessante ver a preocupação de todo mundo sobre a falta de conexão da universidade com a sociedade. E nós estávamos numa universidade norte-americana muito importante, numa cidade universitária de Nova Inglaterra e uma das coisas que discutimos é que as universidades de campus não simplesmente se isolam das cidades, mas, quando são fechadas para as férias escolares, elas são fechadas mesmo. Não é uma questão de dizer: "olha, tem esse espaço imenso e tem esse espaço vazio, por que as pessoas não vêm pra cá?" Por que grupos, movimentos populares não podem fazer suas oficinas e usar a biblioteca nos meses em que não há aulas ou, melhor ainda, de maneira constante? Por que a universidade pública não pode ser, na prática, pública? As suas bibliotecas são abertas para o público? Se você é uma simples pessoa de rua, você pode entrar numa universidade brasileira e estudar na biblioteca. As nossas universidades, cheias de informações, que são bens públicos, são fechadas! E isso me preocupa muito. A construção da desigualdade começa nos espaços de saber...

Leny - Você estava falando e eu me lembrando de uma discussão que houve há alguns anos na USP sobre o fechamento dos portões.

Peter - Fechar fisicamente é simplesmente o fim de um processo de fechar conceitualmente; para privatizar fisicamente você já precisa ter construído o fechamento enquanto processo social. É um coup de grâce. Na Inglaterra, pessoas como o historiador E.P.Thompson eram extremamente ativas na Universidade, mas não nas salas de aula de pósgraduação e sim nos cursos de extensão, na educação popular. O que se chama de WEA (Workers Education Association) é um movimento muito forte, uma associação de professores, sindicatos, trabalhadores etc... que criou uma malha de cursos de extensão gratuitos. Eu lembro de pessoas em Manchester, meus pais e seus amigos, por exemplo, que não foram para a universidade, indo para cursos na universidade sobre a arqueologia romana na Inglaterra.

${ }^{39}$ Garfinkel, H. (1994). Studies in ethnometodology. New Jersey: Prentice Hall. 
Os cursos eram à noite, ministrados por professores catedráticos que entenderam que parte da função da universidade é a sua abertura para a população, que os bens públicos produzidos e reproduzidos nas universidades precisam ser de fato públicos. Estamos muito longe disso... Estou falando, literalmente, de uma situação onde você, Leny, sem precisar mostrar nenhum certificado para ninguém, pode se inscrever em um curso de literatura medieval, porque você quer saber sobre literatura medieval e quem vai dar o curso é um dos ou uma das mais importantes especialistas na área!

Leny - Parece tão lógico...

Peter - Parece tão lógico... mas é ainda tão distante. Bem, nós estamos aqui neste programa de gestão pública e cidadania, tentando cutucar um pouco disso, mas temos muito ainda para andar e muito para aprender sobre como agir nos espaços e conexões entre disciplinas, de tentar construir pontes para uma certa transdisciplinaridade.

Leny - A Arakcy [Martins Rodrigues] disse que como ela achou muito difícil trabalhar interdisciplinarmente, ela resolveu, ela mesma, ser interdisciplinar...

Peter - A Arakcy era interdisciplinar... isso era uma das suas características e competências marcantes. Tem pessoas que não gostam disso, acham que você está fugindo da raia... mas não penso assim, ao contrário, temos que buscar as conexões com as demais disciplinas, como também temos que saber voltar para atrás e buscar o patrimônio de nossa própria disciplina, recuperar idéias e argumentos que foram jogados no lixo virtual... como por exemplo as idéias de Kurt Lewin.

Leny - Eu estava pensando nele.

Peter - Se você avaliar a produção de Kurt Lewin com os olhos de hoje, você provavelmente vai dizer que ele era subjetivista. Agora, hoje, se estivesse vivo, ele seria provavelmente construcionista. O seu jeito de pensar estava indo nesta direção. Aliás, Arakcy e eu discutimos muito o Lewin e foi ela quem me chamou a atenção às idéias de Lewin sobre canais (channel theory). Ela sempre falava: "esta idéia é genial e tem que ser mais utilizada!" Bem, eu estava no meio de uma dessas reuniões discutindo pobreza e aí pensei: "diabo, é aqui!"

Leny - É aqui que serve!

Peter - As idéias são apresentadas num pequeno capítulo sobre psicologia ecológica no livro sobre Field Theory, que foi organizada depois da morte dele. Lewin discute uma pesquisa sobre hábitos de comida, onde o objetivo era responder à seguinte pergunta: "por que as pessoas comem o que comem?" E o Kurt Lewin responde que, de fato, essa não é a questão. A grande maioria das pessoas, a não ser os mais ricos, comem o que está na mesa. Não há escolha à mesa; come-se o que está na mesa. Consequentemente, a pergunta é outra... como a comida chega à mesa?

Ao responder esta questão, Lewin estuda todos os canais a partir dos quais a comida é posta na mesa. Passando por conceitos de comida, formas de produção, formas de guardar, armazenar, hábitos culturais, papéis sociais, tecnologia de equipamento de cozinha e tudo mais, incluindo os bloqueios e as restrições. Em cada momento da cadeia ou em cada momento no canal, ele identifica os porteiros que podem abrir ou fechar as possibilidades, que ele chama de gatekeepers. Estes são os mesmos processos que estávamos analisando em relação à pobreza. Como crianças chegam à escola, quais os bloqueios para o pequeno produtor, quais os canais para obter documentos e acessar empréstimos. O modelo de análise fornece um caminho para entender o cotidiano enquanto lugar de conflito, de restrições, de possibilidades e barreiras.

Leny - Peter, como você relaciona estas suas experiências com a formação de alunos na área de pesquisa, para poder fazer pesquisa aplicada desta maneira... 
Peter - Eu diria que é possível falar primeiro do desenvolvimento de um repertório grande de práticas de pesquisa. Não enquanto instrumentos estéreis de medição, mas enquanto formas de diálogo. Isso é muito importante. Se você não sabe buscar o diálogo, você não vai achar o campo, porque o campo não é lá fora, é em frente de seu nariz! $\mathrm{O}$ campo começa onde o teu nariz termina, é lá! Me lembra Camões: "onde a terra termina e o mar começa!" Então: "onde o nariz termina e o campo começa!" Então se alguém não te ajudou a entender como se insere no dia-a-dia, nas formas múltiplas de diálogo, se alguém só te treinou a conceber pesquisa como algo frio, mecânico, que te distancia de tudo isso, você vai para lugar nenhum! acabadas..

Leny - É o distanciamento através de grandes teorias e explicações prontas e

Peter - Sim, e também a ênfase exagerada em instrumentos de medição, questionários e escalas. É necessário aprender que você pode mergulhar no dia-a-dia, que você pode ir captando aquilo que acontece, anotando de maneiras diferentes, aceitando a aparente bagunça do dia-a-dia e que isso é fazer pesquisa tanto quanto o trabalho de laboratório. O segundo ponto: você também não vai a lugar nenhum se você não consegue pensar amplamente, se você não tem lido sobre a sociedade, se você não acompanha um pouco do que acontece na história, na ciência política, na sociologia, na antropologia social e na filosofia. É preciso, em outras palavras, reconhecer que a psicologia faz parte das ciências sociais e que não precisamos pedir permissão a ninguém para isso e muito menos nos sentir de menor porte; ao contrário, nós temos a nossa contribuição e devemos assumi-la com coragem e convicção.

Terceiro, penso que é muito importante fazer a conexão com as questões atuais da sociedade dentro da sala de aula. Não porque é uma boa técnica didática, mas porque sem isso não há conhecimento. Karl Popper comentou que sem problemas não há conhecimento, mas também sem conhecimento não há problemas. A observação é instigante; como sabemos que temos problemas? George Mead vai ser mais radical ao se referir ao conhecimento; para ele o conhecimento é produzido no momento da resolução de problemas. Então, como deve ser o ensino? Se ensinamos somente teoria, estamos transferindo conhecimento ou simplesmente transferindo teoria? Penso com toda a seriedade que temos muito mais aulas do que precisamos. Os alunos devem temer quando discutimos reforma curricular, porque o resultado é sempre mais aulas.

Leny - E na área de formação em psicologia organizacional, o que precisamos fazer?

Peter - Penso que a primeira coisa a fazer é parar de falar sobre psicologia de organização e trabalho como se fossem sinônimos de empresa e recursos humanos, seja no lado empresarial, seja no lado contrário, porque ambos se reproduzem. Na PUC, faço questão, na primeira aula, de deixar claro que não pretendo falar sobre empresas a não ser, talvez, na $15^{\mathrm{a}}$ aula e, mesmo assim, numa discussão sobre privatização do público. Aí alguém sempre diz: "mas professor?!"

Leny - "Eu vim aqui pra isso!"

Peter - Eu digo: "porque gastar o tempo inteiro sobre algo que é simplesmente um pedacito de um fenômeno maior: os processos sociais organizativos vistos do lado dos agentes destes processos?" Penso que é possível construir uma outra psicologia organizacional e estou me dedicando a isso; mas ela exige uma leitura um pouco mais ampla das questões e muito prática para mostrar que podemos abrir mão da preciosidade metodológica da investigação. Você, Leny, parou de ficar preocupada sobre métodos depois de passar não sei quantas horas 
a andar de ônibus. E depois escreveu na sua dissertação ${ }^{40}$ : "o que eu fiz era andar de ônibus, escutando pessoas e conversando com elas e pronto!” Ninguém reclamou, ninguém perguntou sobre seu procedimento? Pessoas aplaudiram porque reconheceram que você buscou de maneira ética e sincera viver junto ao dia-a-dia do motorista e fazer um relato honesto do que você aprendeu... é isso que é importante e é para isso que temos que brigar. Recolocar a psicologia, pelo menos a psicologia social, de volta nas ciências sociais é um passo essencial; se não, teremos de conviver para sempre com pessoas que acham que o que fazemos é uma versão de segunda mão da fisiologia, da biologia ou da botânica!

Leny - Ampliando a leitura sobre psicologia organizacional e do trabalho, você possibilita que iniciativas dos alunos possam se tornar estágios: trabalhar com movimentos de bairro, ou ir para uma cooperativa, ou fazer um trabalho...

Peter - Sim, mas vamos sempre, daqui para frente, separar "organização", ou melhor, "processos organizativos" de "trabalho" e lembrar que às vezes estão juntos, mas muitas vezes não. Tem processos organizativos que resultam em organizações, tem processos organizativos entre organizações e tem simplesmente processos organizativos. Tem organizações que se caracterizam em termos de trabalho (work organizations) e também há muitos processos organizativos que seriam descaracterizados se você fosse juntá-los com organizações de trabalho. Movimentos sociais, organizações de protesto e muitos dos pequenos processos do dia-a-dia... Há também trabalho enquanto categoria de análise e há os múltiplos jeitos de tentar sobreviver no dia-a-dia... Não sou uma pessoa que pense haver bons momentos de viver e maus momentos, como se os processos históricos tivessem seus altos e baixos; há sim, momentos muito difíceis e, sem dúvida, estamos enfrentando um destes atualmente... Mas é por isso que existimos enquanto disciplina profissional... para ser útil. Aliás, seria bom colocar uma placa dentro e fora de todas as salas de aula, departamentos e institutos de psicologia, como também nas múltiplas sociedades e associações da classe com uma simples frase: "a psicologia e os psicólogos são de utilidade pública”...

Leny - Bom Peter, sempre é bom conversar com você. Te agradeço pela entrevista.

40 Sato, Leny (1991). Abordagem psicossocial do trabalho penoso: estudo de caso de motoristas de ônibus urbano. Dissertação de Mestrado, Pontifícia Universidade Católica de São Paulo, São Paulo. 